\title{
Book review \\ De velhas e novas humanidades, velhos e novos estudos de média: uma leitura crítica de Blow up the humanities e Greening the media
}

\section{Book review \\ Of old and new humanities, of new and old media studies: a critical review of Blow up the Humanities and Greening the Media}

\author{
Sofia Sampaio* \\ * Centro em Rede de Investigação em Antropologia (CRIA), ISCTE-Instituto Universitário de Lisboa
}

\section{Resumo}

\begin{abstract}
O artigo faz uma leitura crítica dos livros Blow up the humanities, de Toby Miller, e Greening the media, de Richard Maxwell e Toby Miller, ambos de 2012, que, a pretexto da análise de duas "crises" - a crise das humanidades e a crise ambiental (ou "eco-crise") - propõem uma renovação das humanidades e dos estudos dos média em linha com a matriz materialista dos estudos culturais. Em ambos os casos, defende-se o alargamento radical dos objectos de estudo e das abordagens, num quadro de "robusta interdisciplinaridade" que combina métodos quantitativos e qualitativos e que valoriza o trabalho académico colectivo e colaborativo.
\end{abstract}

Palavras-chave: humanidades; estudos culturais; estudos dos média; (eco-)crise; universidade.

\section{Abstract}

\begin{abstract}
The article develops a critical reading of the books Blow up the humanities, by Toby Miller, and Greening the media, by Richard Maxwell and Toby Miller, both published in 2012, which take two ongoing "crises" - the crisis in the humanities and the environmental crisis (or "eco-crisis") - as a starting point to propose a renovation in the humanities and in media studies that seeks to recover the materialist strand of cultural studies. In both cases, a radical expansion of the objects and approaches is defended, within the framework of a "robust interdisciplinarity" that combines quantitative and qualitative methods and that values collective, collaborative work.
\end{abstract}

Keywords: humanities; cultural studies; media studies; (eco-)crisis; university.

O futuro das humanidades não é um assunto da ordem do dia. As disputas que tiveram lugar no mundo anglófono durante a década de noventa e que ficaram conhecidas como culture wars ${ }^{1}$ podem ter deixado marcas profundas dentro e fora da academia, mas perderam a visibilidade e a premência desses tempos. Em Portugal, o debate sobre o futuro das humanidades e os estudos culturais (que não esteve isento das suas polémicas) resolveu-se, até certo ponto, com soluções mais ou menos administrativas que passaram pela remodelação e a criação de cursos e programas de estudo para acompanhar as tendências internacionais dos "novos tempos".2

\footnotetext{
${ }^{1}$ Atribuída ao sociólogo James Davison Hunter (1991), a expressão "guerras culturais" foi rapidamente apropriada e disseminada por figuras conotadas com o Partido Republicano. Mais recentemente, a tese de que a sociedade americana se encontra polarizada por questões estritamente culturais tem sido posta em causa (cf. Thomson, 2010). Mais do que descritiva, trata-se de uma expressão performativa que importa compreender no contexto em que surgiu e singrou.

2 Sobre a "crise das Humanidades" e o papel dos estudos culturais no contexto nacional, veja-se Sanches (1999); Ribeiro \& Ramalho (1999); Aguiar e Silva (2010); Martins (2010; 2015); e Sampaio (2013).
} 
Para nos recordar do que esteve (e está) em causa nestes debates vale a pena ler os dois livros de Toby Miller, Blow up the humanities e Greening the media, ambos de 2012. Não sendo publicações recentes, os dois livros merecem uma leitura atenta, como espero demonstrar. Escrito em co-autoria com Richard Maxwell, o último foi tema da conferência que Miller proferiu no $\mathrm{V}$ Encontro da Associação de Investigadores da Imagem em Movimento (AIM), realizado no Instituto Universitário de Lisboa (ISCTEIUL), em Maio de 2015. ${ }^{3}$ Apesar de Greening the media ser uma intervenção directa no campo específico dos estudos de média, há vantagens em ler os dois livros em conjunto, já que Blow up the humanities identifica e discute o contexto histórico, conjuntural e (meta-) teórico que subjaz e viabiliza algumas das abordagens defendidas para aquele campo. De então para cá, Miller publicou e editou outras obras que tratam e aprofundam as mesmas preocupações, mas que, por razões de espaço, não serão aqui

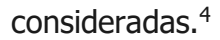

Se há autor capaz de oferecer uma reflexão informada e estimulante quer sobre as humanidades quer sobre os média é, certamente, Toby Miller, que conta com uma importante e já longa carreira nesses domínios, repartida entre o Reino Unido, a Austrália, os Estados Unidos e a América Latina (sobretudo México, Brasil e Colômbia). ${ }^{5}$ Com mais de trinta livros publicados como único autor, co-autor ou organizador em áreas tão diversas como os estudos fílmicos e de televisão, os estudos de cidadania, as políticas da cultura, a economia política dos média e os estudos de género, Miller habituou-nos já a uma argumentação arrojada, que lança mão a dados empíricos e conceitos teóricos sofisticados para desconstruir "verdades" ditas irrefutáveis e trazer para o debate posições marginais ou controversas. 0 estilo coloquial e iconoclasta (quando, por exemplo, se refere a Jacques Lacan como "Jacques-the-Lack" - Miller, 2012, p. 9) poderá perturbar os mais acólitos, mas também resulta numa maior proximidade com o leitor. E é inegável o gosto do autor pela polémica, em linha com um tipo de prática intelectual e académica que procura definir-se, acima de tudo, em relação ao espaço público, visando a identificação e a tomada de posições políticas de forma explícita e fundamentada.

É esse, aliás, o objectivo da intervenção de Blow up the humanities que, em quatro capítulos, discute a actual (e delongada) "crise" das humanidades nos Estados Unidos da América, onde o autor tem vivido e leccionado desde inícios dos anos 1990, com o objectivo de apresentar uma alternativa. Ela aparece com a designação de "Humanidades Três", uma proposta que pretende dar continuidade ao projecto das humanidades engendrado pelos estudos culturais ("Humanidades Dois") durante o processo de contestação dos pressupostos teóricos e epistemológicos que definiam (quase sempre tacitamente) o campo instituído das humanidades ("Humanidades Um"). Este esquema hegeliano, que poderá trair a relação criativa que o autor tem mantido com o campo marxista, defende, enfim, que o projecto das Humanidades Dois não tem conseguido "erguer-se" (a referência ao conceito de Aufhebung é um acrescento meu) de forma a superar velhos "fantasmas" e limitações, pelo que deve ser repensado e reteorizado.

\footnotetext{
${ }^{3}$ A conferência foi gravada em vídeo, estando prevista a sua publicação no sítio oficial da AIM.

${ }^{4}$ Tais como: The SAGE Handbook of Television Studies (2014); Greenwashing Sport (2017); The Routledge Companion to Global Popular Culture (2017). Para actualizações mais recentes, veja-se a página electrónica do autor, em: http://www.tobymiller.org

${ }^{5}$ Chegado à Universidade de Murdoch, em 1986, Toby Miller viveu os inícios dos estudos culturais da Austrália (cf. Stratton 2016) até se mudar para os Estados Unidos (Universidade de Nova Iorque), em 1993. Sobre os interessantes meandros que o seu percurso conheceu fora da academia, veja-se o artigo autobiográfico publicado no Times Higher Education (Miller, 2013b).
} 
Baseando-se na sua experiência profissional, o autor começa por identificar as Humanidades Um com os centros universitários prestigiados (a chamada Ivy League), que recebem a maior parte do financiamento público. Apesar de atraírem um número superior de alunos, as Humanidades Dois não contam nem com o reconhecimento nem com os recursos económicos das primeiras. Nas Humanidades Um, imperam as disciplinas tradicionais (literatura, história e filosofia); nas Humanidades Dois, dominam as "nãodisciplinas" ou "anti-disciplinas", como os estudos de comunicação e média e os estudos culturais, às quais acorrem com entusiasmo os principais beneficiários da democratização do ensino superior americano iniciada em finais dos anos 50 do século passado. As Humanidades Um têm por missão transmitir os "valores" que permitem a distinção entre "civilização" e "barbárie" (com importantes consequências para as questões de classe, religião, nação e outras); dedicam-se, por outras palavras, à reprodução de modelos culturais e sociais sancionados. Já as Humanidades Dois estão vocacionadas para a formação de profissionais, i.e. para a produção de peritos e especialistas com ligações directas ao mercado de trabalho. A divisão de classes é clara: nas Humanidades Um afluem as classes privilegiadas, detentoras de capital económico e cultural, que tenderão a reforçar as elites intelectuais e o status quo; às Humanidades Dois chegam os estudantes oriundos de meios sociais desfavorecidos, em busca de uma mobilidade social cada vez mais limitada.

Esta divisão tem que ser vista no contexto (ou "conjuntura") em que ambos os tipos de humanidades operam: perda geral de alunos nas humanidades (relativamente às outras áreas); quebra acentuada do investimento público no ensino superior - com as humanidades a receber, em 2010, uns parcos $0.45 \%$ dos fundos destinados à investigação (Miller, 2012, p. 12); pendor cada vez mais profissionalizante do ensino superior; proletarização do pessoal académico (geral, mas particularmente sentida nas humanidades), com perda de estabilidade profissional e rendimentos; endividamento dos estudantes, instados a investir em "capital humano" (o seu); adopção de modelos de gestão universitária que mimetizam a gestão empresarial, à luz de concepções do ensino superior como uma "indústria competitiva" e dos estudantes como "clientes" ou "consumidores" (Miller, 2012, p. 18). Há que destacar esta última característica por promover e normalizar práticas que canalizam os (parcos) recursos das universidades para áreas antes marginais ou inexistentes, nomeadamente: a monitorização da "qualidade" (que passou a ser feita numa base permanente e a todos os níveis); a cedência de recursos públicos altamente qualificados e especializados (investigadores, laboratórios, equipamentos) a entidades privadas para que possam realizar pesquisas consideradas dispendiosas ou arriscadas (o autor descreve esta prática como a consagração de um autêntico "Estado Social para empreendedores" - Miller, 2012, p. 23); e o aumento do número de gestores e assessores (com remunerações atraentes) que, em geral, revelam uma crença fetichista na mudança e uma profunda desconfiança em relação à academia (Miller, 2012 , p. 27). ${ }^{6}$

O livro divide-se em quatro capítulos: no primeiro, faz-se um breve resumo da história das humanidades nos Estados Unidos; no segundo, é-nos oferecido o panorama editorial nesta área; no terceiro, são analisadas as "indústrias criativas" - uma das respostas mais recentes e bem conhecidas (inclusive no

\footnotetext{
${ }^{6}$ Vale a pena concretizar: a percentagem de estudantes inscritos em humanidades (8-12\%) era, na altura em que o livro foi escrito, metade da percentagem da década de 1960 e a mais baixa de sempre, contrastando com os aumentos de $176 \%$ e $616 \%$ nas áreas de "business" e de comunicação e média, respectivamente (Miller, 2012, p. 6). Desde 1980 as propinas aumentaram 827\% (Miller, 2012, p. 23); actualmente, o pessoal docente representa apenas um terço das contratações da universidade americana (Miller, 2012, p. 25).
} 
nosso país) à crise das humanidades; finalmente, no quarto capítulo, é avançada a proposta de uma "terceira via", as Humanidades Três, que pretende identificar as lacunas e as limitações das anteriores versões para responder à pergunta: "que sentido de interesse público deve informar as humanidades?" (Miller 2012, p. 93). Seria difícil dar conta da totalidade e riqueza dos dados e argumentos apresentados em cada um dos capítulos, pelo que destacarei apenas alguns.

Segundo o autor, a história das humanidades nos Estados Unidos tem vindo a oscilar entre uma visão "desinteressada" e uma visão "pragmática" do ensino superior, considerado, em larga medida, como um "bem privado" e não um "bem colectivo", i.e. como um entitlement (que deve ser pago por cada um) e não um right (ao qual todos devem ter acesso). A verdade é que, mesmo na sua versão mais "olímpica", as Humanidades Um foram sendo colocadas ao serviço de vários projectos sociais - desde a integração dos imigrantes, em que se procurou beneficiar os grupos brancos de ascendência anglo-saxónica e credo protestante (os chamados WASP) até à construção e consolidação de um tipo de cidadania masculinista e marcial, que tem servido os sectores militares e imperialistas. Apesar da expansão das Humanidades Dois, as Humanidades Um continuam a dominar em várias frentes, designadamente, na esfera editorial. Num exercício de imersão num mundo que Miller conhece muito bem, são-nos enunciados os problemas e os desafios que confrontam os académico que publicam, envolvendo aspectos como as leis da propriedade intelectual, as pressões sobre editoras e bibliotecas, as práticas de ghostwriting, as incógnitas do acesso aberto e, em geral, os conflitos entre interesses privados e interesses públicos. Miller refere os desafios das chamadas Humanidades Digitais (que define com lúcida e refinada ironia - Miller, 2012, p. 59, nota 3), rejeitando argumentos "cibertarianos" que atribuem às tecnologias uma espécie de agencialidade própria (libertadora) que presume a inexistência ou a inutilidade de qualquer tipo de acção política ou institucional (Miller, 2012, p. 53). Se há lugar para alternativas (e o autor acredita que sim), elas terão que passar por acções colectivas concretas, de que nos são dados alguns exemplos (Miller, 2012, pp. 61-62). No final do capítulo, ressaltam dois dados, com efeitos paradoxais, sobre este mundo editorial: por um lado, o facto (negativo) de as humanidades constituírem um campo demasiado pequeno para poderem influenciar as grandes tendências nesta área; por outro, o facto (positivo) de o livro, enquanto objecto, e a leitura, enquanto prática, continuarem demasiado presentes no dia a dia das pessoas para que as humanidades possam ser facilmente descartadas.

De certo modo, a disponibilidade para se envolverem com o "mundano", sobretudo através das indústrias criativas, foi responsável pelo recente impulso das Humanidades Dois. Este é um tópico que ocupa o autor há já alguns anos e que lhe é particularmente caro. Uma das influências formadoras de Miller foi o ramo das políticas culturais (cultural policy), que surgiu, com grande êxito, no seio dos estudos culturais australianos, associado a nomes como Tony Bennett, Stuart Cunningham, Tom O'Regan e Colin Mercer, com quem Miller trabalhou directa ou indirectamente ao longo da sua carreira (Miller, 2012, p. 71; p. 122; cf. Miller, 2013a; Miller, 2015). O autor viria a desenvolver uma linha semelhante do outro lado do Atlântico (Miller \& Yúdice, 2002), onde elaborou uma análise crítica do conceito de indústrias criativas (Miller, 2004) que dificilmente fazia antever a afirmação (central ao argumento deste livro) de que as indústrias criativas constituem "a resposta mais interessante e produtiva à crise das humanidades" (Miller, 2012, p. 64).

As críticas não foram esquecidas: Miller aponta a ligação destas indústrias à crescente financeirização da economia, que pressupõe a sobre-extracção de valor (cultural, intelectual e artístico) de jovens criadores 
submetidos a intensos processos de precarização e proletarização laboral. Ou seja, o autor continua a sublinhar a relação das indústrias criativas ao projecto neoliberal da Nova Direita, que faz remontar ao tempo de Ronald Reagan como Governador da Califórnia, em 1966 e, mais recentemente, à sistematização teórica destas ideias por Richard Florida (2002). Como, de resto, Miller não deixa de apontar, as indústrias criativas mobilizam um conceito de "criativo" que carece de rigor (Miller, 2012, p. 80), diagnosticando problemas e implementando soluções que resultam mais da convergência de políticas públicas e interesses privados não-declarados (com o auxílio de grandes campanhas de promoção) do que propriamente de teorias e práticas sujeitas a escrutínio científico ou democrático. São escassas e pouco credíveis as evidências dos benefícios que as indústrias criativas produzem a longo prazo nas cidades que se propõem a regenerar (Miller, 2012, pp. 81-82). Através do exemplo dos videojogos, que motivaram, nos Estados Unidos, uma poderosa colaboração entre a universidade, a indústria de cinema e o Pentágono, o autor demonstra ainda a cumplicidade que se estabeleceu entre as indústrias criativas, a "masculinidade marcial" das Humanidades Um e as mais recentes intervenções bélicas do Estado americano no palco internacional.

Face a tudo isto, porquê ver nas indústrias criativas uma resposta produtiva? Não obstante os seus defeitos, o autor acredita que as indústrias criativas fizeram aumentar o respeito (dentro e fora das humanidades) pelas Humanidades Dois; aproximaram aquilo que C.P. Snow designou, nos anos 1950, por "duas culturas" - a cultura científico-tecnológica e a cultura humanística; chamaram a atenção para a importância da cultura (e, por extensão, das humanidades) na economia e na sociedade; e tornaram os meios académicos mais favoráveis à interdisciplinaridade (Miller, 2012, pp. 64; 68; 79). Por outras palavras, Miller reconhece o potencial das indústrias criativas para fundirem as Humanidades Um e Dois e forjarem uma aliança (antes considerada impossível) entre intelectuais e técnicos, "poetas e totós" (Miller, 2012, p. 67).

É neste potencial que Miller se inspira para propor uma "terceira via", capaz de superar umas Humanidades Um anquilosadas num conservadorismo elitista e desfasado da realidade e umas Humanidades Dois capturadas pelas indústrias criativas e, consequentemente, pela agenda política a que estas se encontram associadas. Ou seja, o autor crê que a actual articulação entre cultura e economia, apesar de actualmente ao serviço das políticas erradas, representa uma oportunidade para as humanidades. A proposta parte da constatação da centralidade da cultura e dos média na sociedade actual (Miller, 2012, pp. 95-96; 107) para advogar o estudo crítico dos processos de significação que emergem dentro desta conjuntura. As Humanidades Três caracterizar-se-ão, muito sumariamente, por uma "robusta interdisciplinaridade" (cf. Miller, 2013a, p. 201), que saberá combinar economia política, análise textual, etnografia e estudos ambientalistas (Miller, 2012, p. 105), recorrer a métodos quantitativos e qualitativos, ignorar fronteiras entre cultura científica e cultura humanística, para analisar e explicar, em toda a sua complexidade, todo o tipo de fenómenos culturais, sociais e políticos da contemporaneidade. Saberá igualmente mobilizar um tipo de trabalho colectivo e colaborativo que não tem tido grande expressão nas humanidades. 0 alargamento radical dos objectos e dos métodos de análise das humanidades é, aliás, um dos dois significados que Miller atribui à expressão blow up: em alternativa a "explodir" as humanidades (uma ideia que não está completamente posta de parte), o autor pretende "enchê-las como um balão", levando-as a testar os seus próprios limites (cf. Miller, 2013a). A 
hipótese do "balão" rebentar paira, inevitavelmente, no ar. Até que ponto as humanidades serão "insufláveis"? Até onde poderão ir ou estarão dispostas a ir para se salvarem?

É possível ver na proposta das Humanidades Três de Miller um regresso ao projecto original dos estudos culturais, na sua vertente mais materialista, de influência Marxista. ${ }^{7}$ A orientação materialista é, de resto, evidente em Greening the media, que se debruça sobre uma das grandes preocupações de Miller: a destruição do planeta pela acção exploradora de um capitalismo ultraliberal sobre humanos e nãohumanos. A Miller junta-se agora Richard Maxwell, especialista em economia política dos média, com o propósito de analisarem o impacto das tecnologias electrónicas de comunicação e informação (TECI) ${ }^{8}$ no ambiente. A questão ambientalista aparecia já no livro das humanidades, que criticara a noção - falsa mas amplamente divulgada - de que as indústrias criativas constituem uma alternativa "limpa" às indústrias tradicionais (Miller, 2012, p. 80). Também as TECI têm sido apresentadas como "limpas", em virtude não só da sua associação a práticas de consumo orientadas para a "plenitude" e o "prazer" dos seus usuários (Maxwell \& Miller, 2012, p. 4), mas também do efeito de "encantamento" que as tecnologias, em geral, têm exercido sobre as sociedades industriais, incentivando atitudes acríticas ou reverenciais. Às TECI têm sido atribuídas qualidades quase totémicas - poderes transformadores ilimitados e ilimitáveis, bons ou maus, que dispensam análises rigorosas. Os mais optimistas reconhecemIhes um potencial criativo, revolucionário e libertador, capaz de transformar consumidores em "prossumidores" (prosumers - Maxwell \& Miller, 2012, p. 14) ou até - nas versões mais cibertarianas em activistas políticos.

A tese dos autores é que estas e outras manifestações de "sublime tecnológico" têm vindo a influenciar os estudos dos média, impedindo-os de prestarem atenção a realidades materiais bem menos sublimes, tais como as condições de trabalho das pessoas que produzem e manipulam estas tecnologias; os efeitos poluentes das TECI a montante e a jusante da sua utilização; a toxicidade dos diferentes materiais e processos de fabrico, com riscos graves para a saúde individual e pública; as guerras e os conflitos que estão na sua origem e que ajudam a perpetuar - i.e. toda a "suja" materialidade que actualmente sustenta estas tecnologias.

É para resolver estas limitações que os autores falam da necessidade de uma perspectiva ética ecológica, uma espécie de "ecologia materialista" (Maxwell \& Miller, 2012, p. 9) que deverá ser incluída na análise dos processos de significação e comunicação associados aos vários média. No início do livro, uma breve revisão do campo (Maxwell \& Miller, 2012, pp. 10-21) dá-nos conta das principais razões que têm impedido os estudos dos média de adoptarem perspectivas ambientalistas, destacando-se a prevalência de uma cultura humanista antropocêntrica, que acredita que a natureza "existe para ser explorada" (Maxwell \& Miller, 2012, p. 11). Mas os autores também reconhecem a existência de estudos mais críticos

\footnotetext{
${ }^{7}$ A questão das "origens" e do "projecto" dos estudos culturais é, sem dúvida, de difícil elaboração. Como vários autores têm sublinhado, há várias origens e vários projectos. Para o efeito, limito-me a remeter o leitor para o trabalho de Raymond Williams, que continua a inspirar abordagens à cultura de pendor materialista (cf. Milner, 2002). Na área da comunicação e dos média, o legado de Williams pode ser encontrado, por exemplo, num autor como Christian Fuchs (2016).

${ }^{8}$ Trata-se da minha tradução do que os autores designam por ICT/ CE - i.e. information and communications technologies e consumer electronics. O primeiro é geralmente traduzido em português pelo acrónimo TIC.
} 
que têm analisado os média não (apenas) enquanto textos, mas (também) enquanto instituições históricas moldadas por agentes económicos, políticos e sociais concretos. Os exemplos são retirados da história da cultura (Roger Chartier, Andrew Ross), da antropologia (García Canclini, Bruno Latour), dos estudos culturais (Raymond Williams) e da economia política dos média (Herbert I. Schiller, Vincent Mosco), cujo trabalho emerge, directa e indirectamente, nas páginas que se seguem.

O livro está estruturado em seis capítulos, com títulos substantivados que identificam os principais actores/objectos que compõem a relação entre as TECI e o ambiente, nomeadamente: os consumidores (cap. 1); as palavras (cap. 2); os ecrãs (cap. 3); os trabalhadores (cap. 4); os burocratas (cap. 5); e os cidadãos (cap. 6). Maxwell e Miller começam por confrontar-nos com a nossa condição (cada vez mais universal) de consumidores - o "individualismo aquisitivo" (Maxwell \& Miller, 2012, p. 141) é várias vezes apresentado como um dos principais responsáveis pela actual "eco-crise" (Maxwell \& Miller, 2012, p. 27). ${ }^{9}$ No entanto, soluções como o "consumo produtivo verde" (green prosumption - Maxwell \& Miller, 2012, p. 24) e a responsabilidade social das empresas são descartadas como insuficientes, tornando-se cada vez mais evidente, no argumento dos autores, que só o desenvolvimento de uma ética ecológica, ou uma "eco-ética" (Maxwell \& Miller, 2012, p. 31) conseguirá inverter as actuais tendências destruidoras. Nos capítulos sobre "palavras" e "ecrãs", a atenção é deslocada da questão das representações (que tem dominado os poucos estudos sobre esta matéria) para a questão do impacto que os próprios média têm sobre o ambiente. A partir de algumas "histórias ecológicas perdidas" - a história da impressão em papel, da fita magnética, do vinil, do filme, da televisão, do ecrã electrónico - apercebemo-nos dos problemas e dos riscos que se escondem por detrás de práticas aparentemente inócuas e "limpas", tais como ler um livro, ouvir um disco ou ver um filme. Apercebemo-nos também que a substituição de uma tecnologia por outra não representa, por si só, um melhoramento: orientado como está para a "desmaterialização", o actual processo de inovação tecnológica faz com que seja cada vez mais difícil avaliar os impactos ambientais (directos e indirectos) dessas tecnologias. ${ }^{10}$

Como o capítulo seguinte demonstra, também se torna cada vez mais difícil saber o que se passa a nível laboral. A "desmaterialização" das TECI no Norte Global tem sido acompanhada pela sua extrema (e por vezes grotesca) "rematerialização" no Sul Global. É aqui, em geografias capitalistas periféricas, que as grandes empresas culturais e criativas conseguem encontrar trabalho desregulado, desprotegido, em regime intensivo e a baixo custo, seja sob a forma de oficinas de manufactura e montagem de aparelhos electrónicos seja sob a forma de grandes produções de cinema em estúdios ou locais "exóticos" de rodagem. O resultado é uma autêntica "linha de montagem global" (Maxwell \& Miller, 2012, p. 90) que começa por ligar o Sul (mineração, ${ }^{11}$ produção parcial, montagem) ao Norte (venda, consumo, descarte)

\footnotetext{
${ }^{9}$ Para os autores, são quatro os problemas que caracterizam esta crise: as alterações climáticas; a poluição extrema e generalizada; a redução de biodiversidade; e o desaparecimento de habitats (Maxwell \& Miller, 2012, pp. 26-27). 10 Por exemplo, se era relativamente fácil relacionar o papel com a desflorestação e um consumo de água elevado, é difícil estabelecer os impactos ambientais de um livro electrónico. Mas as perspectivas não são animadoras: segundo os autores, a energia que gastamos a ler na internet durante meia hora é equiparável à energia que gastamos a ver televisão durante 90 minutos ou a imprimir um jornal (Maxwell \& Miller, 2012, p. 63). Para além disso, contrariando as previsões mais optimistas, a produção e o consumo de papel têm vindo a aumentar (Maxwell \& Miller, 2012, p. 61), tal como a quantidade de energia gasta pelas TECI (quer ao nível de servidores quer ao nível de utilizadores). Sobre o papel, veja-se ainda Maxwell \& Miller, 2012, pp. 126-127.

${ }^{11} \mathrm{O}$ contributo das minas para as TECI não é de subestimar. Segundo os autores, em 2008, estas tecnologias absorveram, a uma escala mundial, $36 \%$ do estanho, $25 \%$ do cobalto; $15 \%$ do paládio; $15 \%$ da prata; $9 \%$ do ouro; 2\% do cobre; e 1\% do alumínio (Maxwell \& Miller, 2012, p. 93).
} 
e este, de novo, ao Sul (recolha, desmontagem, reciclagem), ${ }^{12}$ num complexo circuito que distribui, de forma assimétrica, trabalho, bens, riscos, doenças e capital entre as populações mais ricas e as populações mais pobres do mundo (Maxwell \& Miller, 2012, pp. 87; 128). ${ }^{13}$

Os dois últimos capítulos centram-se à volta de dois actores essenciais: os decisores-burocratas (com sede dentro e fora do Estado) e os cidadãos. Uma breve história do pensamento burocrático sobre as TECI confirma a prevalência, também aqui, do "sublime ecológico", cujo principal efeito ideológico é o de ofuscar as reais condições de trabalho e o efectivo grau de degradação do ambiente. A isto acresce uma burocracia antropocêntrica que se dedica à amena gestão de riscos e que se encontra dominada por instrumentos de medição como a análise de custos e benefícios (CBA), que atribui um valor monetário a todos os factores ambientais, humanos e não-humanos. Os autores sublinham ainda a captura dos interesses públicos por interesses privados, dando como exemplo o programa de controlo de consumo de energia, em conformidade com uma economia de design inteligente (smart-design economy), que prevê que as empresas do sector sejam compensadas pela perda de lucros, independentemente das medidas implementadas poderem vir a ter um efeito contrário, de incentivo ao consumo (o chamado "efeito ricochete" - Maxwell \& Miller, 2012, pp. 119-123).

Lamentando as lacunas existentes na lei e as fragilidades da sua aplicação, Maxwell e Miller chamam a atenção para o que permanece fora da esfera da legalidade, em sectores informais como os do tráfico mundial de lixo electrónico (Maxwell \& Miller, 2012, pp. 104-105). No entanto, não deixam de elogiar as orientações legislativas que, desde os anos 1970, têm produzido bons resultados (sobretudo no continente europeu), ${ }^{14}$ entre as quais destacam: o princípio da precaução, que permite travar a introdução de novas substâncias sem necessidade de comprovação científica; a proibição ou abolição de poluentes e toxinas com danos para a saúde comprovados; o princípio de desenvolvimento sustentável, que defende os direitos das gerações futuras; ou mesmo o princípio, mais recente, de "responsabilização alargada do produtor", que obriga as empresas a internalizar custos ambientais que têm sido, por norma, externalizados (Maxwell \& Miller, 2012, p. 129). Os autores reconhecem a importância das boas políticas públicas, mas é para os cidadãos, e não para os tecnocratas, que remetem a tomada de decisões.

O que nos leva à questão da "cidadania verde". Como vem sendo habitual neste tipo de discussões, a questão da "governança global" (Maxwell \& Miller, 2012, p. 109) é apresentada como a única solução para os actuais problemas ambientais. A cidadania activa que os autores defendem é, por isso mesmo, uma "cidadania global" (Maxwell \& Miller, 2012, p. 139), que ultrapassa limites territoriais e rejeita projectos de salvaguarda ambiental assentes na ideia de um "património nacional" (Maxwell \& Miller, 2012, p. 137). Por outro lado, a importância das economias nacionais enquanto contrapeso do capitalismo global também é reconhecida (Maxwell e Miller 2012, p. 107), bem como os riscos de uma cidadania global se transformar num instrumento de imperialismo cultural ou numa expressão de cripto-colonialismo (Maxwell e Miller 2012, p. 137). A questão fica por resolver. No final, a figura do "cidadão verde global"

\footnotetext{
12 É o momento dos "catadores" (Brasil) e "pepenadores" (México) - i.e. trabalhadores de fim de linha cuja função é tratar, na expressão inspirada dos autores, os "efluentes dos afluentes" (Maxwell \& Miller, 2012, p. 90).

${ }^{13}$ Apesar das mudanças que entretanto se verificaram (Maxwell e Miller, 2012, p. 97), este circuito reflecte a Nova Divisão Internacional de Trabalho que emergiu depois da segunda guerra mundial, no contexto pós-colonial. Veja-se também o conceito de Nova Divisão Internacional de Trabalho Cultural que Miller desenvolveu, com outros autores, a propósito de Hollywood (Miller et al., 2005).

${ }^{14}$ Mesmo antes de Trump, o desempenho dos Estados Unidos nas questões ambientais não resiste a comparações com o continente europeu, cujo ímpeto regulador e consequentes resultados os autores não deixam de elogiar.
} 
desaparece para dar lugar à figura do "contabilista do futuro", que consegue mobilizar os recursos imaginativos dos autores para a construção de uma alternativa utópica, que designam por "contabilidade verde" ou "ecológica". Quer o objectivo quer os meios desta contabilidade são ambiciosos - subordinar os interesses económicos aos interesses ambientalistas através de um exercício de medição que pretende "tudo contabilizar" (Maxwell \& Miller, 2012, p. 149) - desde as condições de segurança no trabalho (tornadas quantificáveis), às emissões (directas e indirectas) de carbono, passando pelas substâncias que interferem na saúde biofísica de humanos e não-humanos, e todo o tipo de "fluxos de desperdício" (Maxwell \& Miller, 2012, p. 148) gerados durante o ciclo de vida das TECI. As promessas da contabilidade verde são muitas: revelar as interligações, actualmente desconhecidas ou ignoradas, entre diferentes organizações, sectores e regiões; provar a impossibilidade de quantificar a totalidade dos impactos nas próximas gerações (Maxwell \& Miller, 2012, p. 153), para desse modo descredibilizar as actuais práticas de gestão de riscos; e, em geral, estabelecer um novo paradigma ecológico para a economia das TECI (Maxwell \& Miller, 2012, p. 155). Trata-se, afinal, de colocar a produção de conhecimento ao serviço de políticas ambientais. As bases desse conhecimento são alargadas, incluindo o recurso a fontes actualmente ignoradas (sindicatos, activistas, investigadores) e a valorização de métodos qualitativos, tais como a análise de biografias de trabalhadores do sector informal (Maxwell e Miller 2012, p. 150). Curiosamente, o trabalho do contabilista do futuro acaba por reflectir o trabalho intelectual e colaborativo que os autores desenvolvem neste livro e que emerge nos estudos de caso que apresentam, ainda que sumariamente, sobre os telemóveis (cap. 1), o livro (cap. 2), o cinema (cap. 3), as maquiladoras mexicanas (cap. 4), os trabalhadores de lixo electrónico (cap. 4) e a campanha ecológica da Walmart (cap. 5). Também Maxwell e Miller recorrem a uma multiplicidade de textos e fontes: comunicados de imprensa, relatórios de empresas (internos e externos), notícias de jornais, tratados e convenções internacionais, guias práticos, instrumentos digitais de cálculo e medição (por exemplo, de emissões ou consumo de energia), entre muitos outros, cobrindo fontes como empresas, agências reguladoras, sindicatos, associações de consumidores, organizações não-governamentais e grupos de pressão. ${ }^{15}$

\section{Conclusão}

Não há dúvidas de que o futuro das humanidades é, nas palavras de Toby Miller, "um assunto muito público" (Miller, 2012, pp. 5-6). As humanidades nunca são apenas um "ornamento da sociedade" (Miller 2012, p. 123), mas uma parte importante do seu funcionamento. Quer sejam mobilizadas para propagar uma dada ideia de cidadania e governança quer sejam colocadas ao serviço do mercado, elas estão necessariamente ao serviço de uma qualquer lógica instrumental. Daí que falar de "crise" nas humanidades seja, em última análise, uma imprecisão: pela sua importância, as humanidades não podem senão existir em estado de crise permanente, no seio da dúvida e da disputa, já que os significados e as missões que se arrogam e que lhes vão sendo atribuídos são um reflexo dos conflitos e das mudanças da própria sociedade. Como Miller demonstra, a instabilidade e a insegurança - face a si mesmo enquanto projecto e face aos outros - acompanharam as Humanidades Um ao longo da sua história (Miller 2012,

\footnotetext{
${ }^{15}$ Nomeadamente: Greenpeace, Basel Action Network, Silicon Valley Toxics Coalition, e CEREAL.
} 
p. 34). Por outro lado, proclamar a importância da cultura não chega para reabilitar as humanidades. $O$ reconhecimento do valor das indústrias criativas veio dar fôlego a uma "nova direita dos estudos culturais" (Miller, 2012, p. 94), mas nem por isso se traduziu no aumento de financiamento para as humanidades (Miller, 2012, p. 76).

E não é claro se a nova proposta conseguirá fazê-lo. As Humanidades Três têm por base o pressuposto de que a cultura (um conceito mais assumido do que definido, que atravessa as esferas da comunicação, da informação, do entretenimento e do lazer) está no centro das sociedades contemporâneas. Este pressuposto implica a aceitação de uma realidade que também é uma visão do mundo, uma economia e ideologia política (dita pós-industrial) que se apresenta simultaneamente como uma virtude e um caminho sem alternativa. Miller não é alheio ao contexto histórico-político que tornou possível esta visão: o declínio do socialismo de Estado e a descrença generalizada num projecto socialista não-utópico que abriu a porta para o autoproclamado triunfo do capital financeiro (Miller 2012, 10; p. 98). A solução apresentada é uma solução pragmática, que tem por objectivo reverter a actual condição de marginalidade das humanidades e assegurar a sua influência no presente e no futuro. É tal o pragmatismo que, perante a crescente presença do capital na academia, o autor não exclui a possibilidade de esta última poder exercer uma influência positiva sobre aquele (Miller, 2012, p. 121).Trata-se igualmente de um pragmatismo nãosectário, disposto a submeter argumentos marginais ou controversos a juízes cépticos ou até hostis. Como o autor, a dado momento, concede: "Não posso dar-me ao luxo de falar apenas para os meus colegas socialistas" (Miller, 2012, p. 118). ${ }^{16}$

Este pragmatismo reaparece, até certo ponto, em Greening the media, onde Maxwell e Miller voltam a procurar um público alargado para fomentar a discussão e a resolução de problemas concretos. Os autores reconhecem a importância que as TECI têm na vida das pessoas (Maxwell \& Miller, 2012, p. 6) e não rejeitam a ideia de poderem vir a existir "usos ecológicos e sãos dos média" (Maxwell \& Miller, 2012, p. 7). Também não deixam de reconhecer aspectos positivos nos movimentos "verdes" dos consumidores, que vêem como uma espécie de "eco-crítica" desenvolvida por baixo (Maxwell \& Miller, 2012, p. 31), ou até no "ambientalismo cosmético" (greenwashing) das empresas, que por vezes vai no sentido certo. Ambos são, afinal, um sinal do interesse que os problemas ambientais têm conseguido conquistar. No entanto, torna-se claro que nem os consumidores nem as empresas poderão constituir uma base sólida para a mudança: aos primeiros falta uma visão política e holística; às segundas falta a vontade de ir para lá de uma "retórica verde" que pretende, acima de tudo, convencer consumidores e agências públicas reguladoras de que a auto-regulação é suficiente (Maxwell \& Miller, 2012, pp. 31; 84).

Ao nível dos avanços tecnológicos - nos quais se continua a depositar a crença (sempre adiada) num "admirável mundo novo" - também não há razões para optimismos. Apesar de persistir a ideia de que as novas tecnologias são sempre melhores do que as antigas, o aparecimento de novos média não tem significado o fim nem de práticas laborais abusivas nem de processos industriais prejudiciais ao ambiente. Velhas e novas tecnologias continuam a existir lado a lado, em relações de interdependência, complementaridade ou até convergência (Maxwell \& Miller, 2012, p. 62), sem que com isso interrompam práticas estabelecidas. Por outro lado, a tendência desmaterializadora das inovações, que nos afasta cada

\footnotetext{
${ }^{16}$ Afinal, o financiamento da investigação depende da angariação de apoios, muitas vezes externos ao campo. O pragmatismo de Miller tem, claramente, limites, não o impedindo de apelar ao boicote internacional de universidades americanas que recebem financiamento para fins militares (Miller, 2012, p. 88).
} 
vez mais da materialidade dos processos de produção, consumo e descarte, assegura que esses processos e os seus efeitos permaneçam fora do escrutínio público.

No final, o grande desafio é construir uma perspectiva ambientalista capaz de contestar e suplantar um modelo económico firmemente arraigado na ideia de "crescimento sustentável" - para os autores, um "mau oximoro" que facilmente se confunde com o conceito (benevolente) de "capitalismo sustentável" (Maxwell \& Miller 2012, pp. 26; 118). A resposta parece residir numa ética ecocêntrica (Maxwell \& Miller, 2012, p. 34), que requer uma mudança de paradigma sem lugar para ideias tecno-deterministas, tecnoprogressistas ou cibertarianas e, muito menos, para o dogma do crescimento (económico). A proposta da contabilidade verde acaba por enveredar, porém, por um caminho mais pragmático, alinhando os autores com uma eco-ética que fica a meio caminho entre a ética ecocêntrica (radical) e a ética ecologista antropocêntrica (insuficiente), segundo a classificação que os mesmos propõem (Maxwell \& Miller, 2012, p. 34). Apesar de oscilar entre possibilidades utópicas e distópicas e de prever conflitos entre a visão ecocrítica e a actual tendência para a gestão de riscos e recursos (ou business as usual), a ficção do contabilista do futuro assenta na possibilidade de agrupar sob o mesmo objectivo consumidores, trabalhadores, reguladores, vendedores e grandes marcas, revelando uma elevada confiança, não apenas na capacidade regeneradora das práticas eco-éticas sustentáveis (que, com o tempo, conseguirão reverter a crise actual), mas também no conhecimento científico como instrumento privilegiado para produzir essa mudança.

Blow up the Humanities e Greening the Media são livros importantes quer pelos diagnósticos que fazem de conhecidos problemas quer pelas soluções, mais ou menos pragmáticas, que sugerem. Apesar de se focarem nos Estados Unidos, as análises e os argumentos que apresentam têm ressonâncias e implicações mais amplas. No centro dos dois livros - justificando uma leitura conjunta - encontramos uma abordagem às humanidades e aos média que, não sendo nova, continua pertinente e por cumprir. Com efeito, muito daquilo que as Humanidades Três e os estudos verdes dos média preconizam foram já defendidos ou até praticados em estudos críticos anteriores, como parte de uma tradição intelectual, directa ou indirectamente reconhecida pelos autores, que rejeita o determinismo tecnológico, o formalismo textual e o "tecno-sublime". Um exemplo dessa tradição é o trabalho de Raymond Williams, que analisou a centralidade da (ideia de) cultura na sociedade burguesa como um processo histórico (Williams, 1961), desenvolvendo perspectivas histórico-materialistas que lhe permitiram estudar a televisão como uma "forma social" (Williams, 1974). Um outro exemplo é o trabalho de David Morley, que tem vindo a "descentrar" os estudos dos média, contribuindo para aquilo que mais recentemente tem chamado de non media-centric e more-than-representational media studies (Krajina et al., 2014). Miller e Maxwell retomam vários aspectos desta tradição - as questões de textualidade, discurso e representação (privilegiadas nos estudos culturais); as questões de recepção, significação e usos (centrais aos active audience studies); e as questões de produção, propriedade e controlo (objecto da economia política dos média) - para configurar um ambicioso programa interdisciplinar que pretende articular níveis de análise "macro" (instituições, regiões, estruturas) e "micro" (experiências, práticas, textos) através de um trabalho colaborativo que envolve semiólogos, teóricos e críticos da cultura, antropólogos, geógrafos, sociólogos, etnógrafos, atravessando fronteiras disciplinares entre humanidades e ciências sociais, conhecimento académico e não académico. Mas o grande contributo destes autores reside, sem dúvida, 
na atenção que dedicam às relações laborais e aos impactos ambientais dos média, que têm sido sistematicamente excluídos da maior parte dos estudos.

No final, o que está em causa - em ambos os livros - é podermos decidir sobre o tipo de sociedade em que queremos viver (Maxwell \& Miller, 2012, p. 40), ou até, sobre o tipo de vida que queremos poder viver. Entrelaçada com a actual eco-crise, encontramos, talvez sem surpresa, a crise das humanidades. Talvez as duas crises sejam, afinal, parte do mesmo problema, cuja solução necessariamente passará pela promoção de um maior e melhor conhecimento sobre o que se passa à nossa volta e a criação de espaços públicos de debate e intervenção verdadeiramente participados e consequentes.

\section{Referências}

Aguiar e Silva, V. (2010). As Humanidades, os estudos culturais, o ensino da literatura e a política da língua Portuguesa. Coimbra: Almedina.

Florida, R. (2002). The Rise of the Creative Class and How It's Transforming Work, Leisure and Everyday Life. Nova Iorque: Basic Books.

Fuchs, C. (2016). Critical Theory of Communication: New Readings of Lukács, Adorno, Marcuse, Honneth and Habermas in the Age of the Internet. Londres: University of Westminster Press.

Hunter, J.D. (1991). Culture Wars: The Struggle to Define America. Nova Iorque: Basic Books.

Martins, M.L. (2010). Os Cultural Studies no Instituto de Ciências Sociais da Universidade do Minho. In M.L. Martins (org.), Caminhos nas ciências sociais: memória, mudança social e razão: Estudos em homenagem a Manuel da Silva Costa (pp. 271-287). Coimbra: Grácio/CECS.

Martins, M.L. (2015). Os Estudos Culturais como novas Humanidades. Revista Lusófona de Estudos Culturais, vol. 3 (1): 341-361.

Maxwell, R. \& Miller, T. (2012). Greening the media. Nova Iorque: Oxford University Press.

Miller, T. (2004). A View from a Fossil: The New Economy, Creativity and Consumption - Two or Three Things I don't Believe in. International Journal of Cultural Studies, vol. 7 (1): 55-65.

Miller, T. (2012). Blow up the humanities. Philadelphia: Temple University Press.

Miller, T. (2013a). A Conversation about Blow-ups: Communication Studies, Critical Studies, Cultural Studies \& the Current Crisis of the Humanities: James Hay interviews Toby Miller. Communication and Critical/Cultural Studies, vol. 10 (2-3): 183-210.

Miller, T. (2013b). Multilayered Intellect. Times Higher Education, January 10. Disponível online em http://www.timeshighereducation.co.uk/multilayered-intellect/422293.article

Miller, T. (2015). Dependencia meets gentle nationalism. Cultural Studies, vol. 29 (4): 515-526.

Miller, T., Govil, N., Mcmurria, J., Maxwell, R. \& Wang, T. (2005). Global Hollywood 2. Londres: British Film Institute.

Miller, T. \& Yúdice, G. (2002). Cultural Policy. Londres: Sage.

Milner, A. (2002). Re-Imagining Cultural Studies: The Promise of Cultural Materialism. Londres: Sage.

Krajina, Z., Moores, S. \& Morley, D. (2014). Non-media-centric media studies: A crossgenerational conversation. European Journal of Cultural Studies, vol. 17 (6): 682-700. 
Ribeiro, A.S. \& Ramalho, M.I. (1998). Dos estudos literários aos estudos culturais? Revista Crítica de Ciências Sociais, vol. 52-53: 61-83.

Sampaio, S. (2013). Portuguese cultural studies/ Cultural studies in Portugal: Some thoughts on the making and remaking of a field. Culture Unbound. Journal of Current Cultural Research, vol. 5: 73-88.

Sanches, M.R. (1999). Nas Margens: Os Estudos Culturais e o Assalto às Fronteiras Académicas e Disciplinares. Etnográfica, vol. 3 (1): 193-210.

Stratton, J. (2016). Perth Cultural Studies: A brief and partial intellectual history. Thesis Eleven, vol. 137 (1): 83-105

Thomson, I.T. (2010). Culture Wars and Enduring American Dilemmas. Ann Arbor: University of Michigan Press.

Williams, R. (1961). Culture and Society: 1780-1950. Londres: Pelican.

Williams, R. (1974). Television: Technology and Cultural Form. Londres: Fontana Press. 